\title{
The impact of hospital overcrowding on postgraduate education: an emergency medicine resident's perspective through the lens of CanMEDS
}

\section{Sam Sabbah, MBBS \\ INTRODUCTION}

According to a position statement by the Canadian Association of Emergency Physicians (CAEP), emergency department (ED) overcrowding is a national problem and the lack of acute care beds has led most Canadian hospitals to frequently operate at unsustainable occupancy levels of greater than $90 \%$. $^{1}$

Although more apparent in the ED, overcrowding is a hospital-wide problem, and is particularly prevalent in tertiary centres. ${ }^{2}$

Residents are the future of the medical profession. The practices and learning environments to which they are exposed undoubtedly influence the attitudes and knowledge that result. Despite this, there is a notable absence of the perspectives of residents in the overcrowding literature.

As a senior resident in the FRCP emergency medicine program at McGill University, I am fortunate to have rotated through many services across 7 different hospitals. I have made a number of observations. First, overcrowding is a bitter reality and not just a statistic. For each increase in rates of bed occupancy or length of stay, there are real patients lying on stretchers in the hallways of EDs, and these patients suffer the consequences of this situation. Second, overcrowding is truly a systemic problem that affects all services inside and outside of the hospital. It has been noted that EDs carry a disproportionate burden of the problem because the $\mathrm{ED}$ is the only department that, as a result of a minimal control over patient input and output, is managed as if it had infinite capacity. This said, the reality is that the entire health care system is overwhelmed, and if it weren't for "in-patient" overcrowding, typically the result of a lack of long-term care availability, EDs would not be so crowded. Failure to fully appreciate this may be a factor in the frequent clashes between emergency physicians and admitting services. Finally, the increased clinical workload and poor care delivery circumstances inherent in overcrowding negatively affect resident education and well-being.

The Canadian Medical Education Directions for Specialists (CanMEDS) defines 7 overlapping "Roles" that are needed for medical education and practice (Table 1 ). ${ }^{3}$ CanMEDS has been integrated into The Royal College of Physicians and Surgeons of Canada's accreditation standards for residency programs and its framework provides a useful lens to discuss the effect of overcrowding on resident education.

\section{CANMEDS ROLES AND OVERCROWDING}

\section{Medical Expert and Scholar}

Overcrowding increases the clinical and administrative workload of residents and attending staff. Although this may increase the volume and diversity of patient pathology to which residents are exposed, it limits the quantity and quality of formal and bedside teaching. ${ }^{4-6}$ It also reduces the time available for reading around cases, looking up information, and preparing for presentations and rounds. In addition, increased resident workload has been linked to high levels of fatigue, sleep deprivation, burnout and psychological distress..$^{7-10}$

\section{Communicator}

In overcrowded academic centres, residents carry out a

PGY-5, McGill Emergency Medicine FRCP Program, Montréal, Que.

Submitted Dec. 29, 2008; Accepted Jan. 15, 2009

This article has not been peer reviewed.

CJEM 2009;11(3):247-9 
significant proportion of the physician-patient communication. Residents may find themselves rushed while interacting with patients. In addition, patients wait longer to see physicians and spend less time with them. Both these factors have been linked to lower patient satisfaction. Therefore, overcrowding could negatively affect a resident's rapport with patients and encourage the development of poor communication habits that trainees will take with them into future practice.

\section{Collaborator and Professional}

Many hospital services feel pressured to not admit patients because of bed scarcity and the high number of patients needing admission. In academic centres, this frequently results in conflicts over which service is responsible for admitting a given patient. Thus the emphasis shifts from collaborating with the various members of the health care team in order to provide the best care for the patient, to reducing the clinical load on services. In addition, the increasingly stressful working environment and confrontations that accompany overcrowding are detrimental to the Professional Role.

\begin{tabular}{|c|c|}
\hline Role & Definition \\
\hline Medical Expert & $\begin{array}{l}\text { Physicians integrate all of the CanMEDS roles, } \\
\text { applying medical knowledge, clinical skills and } \\
\text { professional attitudes in their provision of } \\
\text { patient-centred care }\end{array}$ \\
\hline Communicator & $\begin{array}{l}\text { Physicians effectively facilitate the doctor- } \\
\text { patient relationship and the dynamic } \\
\text { exchanges that occur before, during and after } \\
\text { the medical encounter }\end{array}$ \\
\hline Collaborator & $\begin{array}{l}\text { Physicians effectively work within a health } \\
\text { care team to achieve optimal patient care }\end{array}$ \\
\hline Manager & $\begin{array}{l}\text { Physicians are integral participants in health } \\
\text { care organizations, organizing sustainable } \\
\text { practices, making decisions about allocating } \\
\text { resources and contributing to the } \\
\text { effectiveness of the health care system }\end{array}$ \\
\hline $\begin{array}{l}\text { Health } \\
\text { Advocate }\end{array}$ & $\begin{array}{l}\text { Physicians responsibly use their expertise and } \\
\text { influence to advance the health and well-being } \\
\text { of individual patients, communities and } \\
\text { populations }\end{array}$ \\
\hline Scholar & $\begin{array}{l}\text { Physicians demonstrate a life-long } \\
\text { commitment to reflective learning, as well as } \\
\text { the creation, dissemination, application and } \\
\text { translation of medical knowledge }\end{array}$ \\
\hline Professional & $\begin{array}{l}\text { Physicians are committed to the health and } \\
\text { well-being of individuals and society through } \\
\text { ethical practice, profession-led regulation and } \\
\text { high personal standards of behaviour }\end{array}$ \\
\hline
\end{tabular}

\section{Health Advocate}

Many residents in overcrowded academic centres feel so overwhelmed by the immediate needs of patients that they cannot devote the time and effort required to advocate for changes in practices and policies.

\section{Manager}

Residents and staff in overcrowded hospitals care for a large number of sick patients. When faced with this situation, the focus shifts from optimum holistic care to the provision of adequate care. Although this may be appropriate as a temporary measure, the risk is "normalization of deviance," whereby residents learn to accept progressively lower standards of care. Most junior residents are outraged at the thought of having their patients spend the night on a stretcher in an ED hallway. With time, however, they learn to accept this practice as a necessary evil, applying band-aid solutions rather than addressing the root cause of the problem. Moreover, as the clinical demands of their patients increase, residents find it increasingly difficult to balance their personal and professional lives. This strain contributes to the development of burnout, leading to inefficiency, which in turn leads to a perception of increased clinical workload, thus exacerbating burnout in a cyclical manner.

\section{THE MCGILL EM RESIDENCY PROGRAM}

In keeping with the spirit of CanMEDS, the FRCP and CCFP-EM emergency medicine residents at McGill University, under the guidance of our program directors and ED chiefs, set out to institute change. We recognized that the first step was to examine the effect of overcrowding on resident education. To achieve this, we conducted a cross discipline survey of residents at McGill University. Of the 970 residents surveyed, 204 replied (21\% response rate). The preliminary results were not surprising. Of those who responded, $70 \%$ reported overcrowding had a moderate to large negative effect on their training, $80 \%$ reported that overcrowding had a moderate to large negative effect on their job satisfaction and quality of life, and $75 \%$ reported that overcrowding had a moderate to large negative effect on rapport with their patients.

Next, we set out to make our voices heard. We held a meeting that included all the McGill emergency medicine residents from the Royal College and CCFP(EM) programs and drafted a "McGill Emergency Resident's 
Position Statement on Hospital Overcrowding." In this statement, which can be found at www.mcgill.ca/ emergency/flow/statement, we presented our perspective on the leading causes of overcrowding, provided recommendations to guide future research and presented key solutions to the problem.

In my view, our efforts at McGill University mark only the beginning of what I hope will be an increased role of emergency medicine residents in advocacy of this nature. The emergency medicine residents across Canada are the future of our specialty, and we share common goals and aspirations that could better unite us. I encourage the emergency medicine residents of Canada to prepare a national emergency resident position statement on overcrowding under the auspices of the CAEP Residents' Section. We have the ability and the duty to advocate for our patients and play a role in improving our health care system. It is incumbent upon us to lead the way to a better future for our patients and our students.

Acknowledgement: I would like to thank my program director, Dr. Ken Doyle, for his guidance, mentorship and support throughout my training and for suggesting CanMEDS as a framework for this discussion.

Competing interests: None declared.

Keywords: residency, medical education, CanMEDS, CAEP, overcrowding, emergency medicine, McGill University

\section{REFERENCES}

1. Canadian Association of Emergency Physicians (CAEP). Position statement on emergency department overcrowding. Ottawa (ON): The Association; 2007. Available: www.caep.ca/template .asp?id=37C951DE051A45979A9BDD0C5715C9FE (accessed 2009 Mar 16).
2. Atzema C, Bandiera G, Schull MJ. Emergency department crowding: the effect on resident education. Ann Emerg Med 2005;45:276-81.

3. Frank JR, Ed. The CanMEDS 2005 physician competency framework. Better standards. Better physicians. Better care. Ottawa (ON): The Royal College of Physicians and Surgeons of Canada; 2005. Available: http://rcpsc.medical.org /canmeds/CanMEDS2005/CanMEDS2005_e.pdf (accessed 2009 Mar 16).

4. Kelly SP, Shapiro N, Woodruff M, et al. The effects of clinical workload on teaching in the emergency department. Acad Emerg Med 2007;14:526-31.

5. Aldeen AZ, Gisondi MA. Bedside teaching in the emergency department. Acad Emerg Med 2006;13:860-6.

6. Haney EM, Nicolaidis C, Hunter A, et al. Relationship between resident workload and self-perceived learning on inpatient medicine wards: a longitudinal study. BMC Med Educ 2006;6:35.

7. Zaré SM, Galanko J, Behrns KE, et al. Psychological well-being of surgery residents before the 80-hour work week: a multiinstitutional study. I Am Coll Surg 2004;198: 633-40.

8. Rosen IM, Bellini LM, Shea JA. Sleep behaviors and attitudes among internal medicine housestaff in a U.S. university-based residency program. Acad Med 2004;79: 407-16.

9. Papp KK, Stoller EP, Sage P, et al. The effects of sleep loss and fatigue on resident-physicians: a multi-institutional, mixed-method study. Acad Med 2004;79:394-406.

10. Thomas NK. Resident burnout. JAMA 2004;292:2880-9.

Correspondence to: Dr. Sam Sabbah, 3550 Jeanne-Mance, Apt. 2804, Montréal QC H2X 3P7; samsabbah@sympatico.ca 